\title{
Special issue: 2nd Congress of the Italian Network on Organic Agriculture Research (RIRAB); Rome, 11-12 June 2014
}

\author{
Paolo Bàrberi
}

Published online: 30 April 2015

(C) Springer Science+Business Media Dordrecht 2015

It is my honour and pleasure to introduce this special issue dedicated to the 2nd Congress of the Italian Network on Organic Agriculture Research (RIRAB), which took place at the National Research Council's (CNR's) headquarters in Rome from 11 to 12 June 2014.

RIRAB is a young network which has the ambition to bring together everyone interested in organic agriculture research, including not only the academia and public and private research institutions/foundations but also private entrepreneurs with an attitude to research. RIRAB is the first attempt, on a national scale, to create a multidisciplinary open discussion forum to highlight priority themes worth of further investigation, taking into account the perspectives of the scientific as well as the productive world. Italy has a vibrant organic sector which, however, was until recently not enough supported by public research and even less by private one. Fortunately, the situation is changing and networks like RIRAB are instrumental to support the change. Those interested to know more about RIRAB are invited to read the Country Overview which opens this special issue, co-authored by RIRAB's President Mauro Gamboni.

The 2nd RIRAB Congress was attended by about 150 delegates from various disciplines. It was structured around three sessions and cross-cutting themes: (i) Rational use of natural resources: an agroecological

P. Bàrberi $(\bowtie)$

Institute of Life Sciences, Scuola Superiore Sant'Anna, Pisa, Italy

e-mail: barberi@sssup.it approach; (ii) Sustainable organic food chains and communication to consumers; and (iii) Biodiversity: a resource for organic livestock farming. This last session was a joint action between RIRAB and the Italian Association for Organic and Biodynamic Livestock Farming (ZooBioDi). The three sessions included invited, platform and poster presentations, and poster digests presented by young researchers. In its final session, the Congress hosted a round table on cutting-edge issues for Italian organic farming which was attended by representatives of various stakeholders. RIRAB's working groups were actively engaged in the scientific organization of the Congress as well as in the selection and handling of the papers which appear in this special issue. The Editorial Board of this special issue selected papers based on quality and innovation while ensuring representativeness to the breadth of themes presently dealt with in Italian organic agriculture research.

This special issue contains seven papers. The first one, by Gamboni and Moscatelli, is a Country Overview showing the recent development of organic agriculture in Italy, the ongoing trends in production, trade, communication and research, and highlighting the sector's perspectives against present and foreseeable consumers' attitudes and policy orientations.

Carbonaro et al.'s paper addresses a case study representative of an important research topic at the country level: the nutritional qualities of organically grown endangered local varieties or ecotypes of pulses like lentil and grass pea. This germplasm was grown in a selection of natural reserves in Central and Southern Italy, with the aim to highlight the potential of bringing together 
organic production, agrobiodiversity conservation and nature conservation. Results showed that cultivars of both crops have peculiar and interesting chemo-physical, technological and nutritional traits, especially as to the array of functional proteins and to the composition of highly bioavailable polyphenols and phenolic acid fractions.

Corsi et al. studied the possibility of using chitosan, especially in the nursery stage, as a stimulator of natural defence barriers of kiwifruit plants to prevent outbreaks from Pseudomonas syringae pv. actinidiae (PSA). If proven successful, elicitors like chitosan could substitute potentially harmful pesticides still widely used in organics like copper. In this work, in vitro cultures of kiwifruit were chosen as model system to study the interactions between chitosan and the host plant. A rapid method to evaluate chitosan effect was developed through molecular markers based on the quantification of pathogenesis-related proteins. The study showed potential in using chitosan as an elicitor of plant defence against pathogens through activation of some enzymes involved in detoxification processes and increasing in plant defence barriers.

Ciaccia et al. investigated the use and management of cover crops as Ecological Service providing Crops (ESC) in organic vegetable systems, with a main focus on weed suppression through competition and allelopathy. Autumn-sown cereal cover crops (wheat, barley, spelt, rye and a mixture) were grown before a melon crop. ESC were flattened by a roller crimper to obtain a mulch layer in which melon was transplanted. The allelopathic potential of ESC was tested through a bioassay test using curly dock seeds (Rumex crispus) as target. At ESC termination, there was no difference in ESC or weed biomass despite a clearly higher weed suppression effect in rye at an earlier stage. This effect was ascribed to higher rye allelopathic effect, as confirmed by bioassay results. Melon total and marketable yield were unaffected by ESC, but the crop had a higher competitive ability against weeds especially after the cover crop mixture.

Calabrese et al.'s study focused on an agroecosystem of recognized ecological as well as cultural value: Mediterranean Ancient Olive Orchards (AOOs), widespread especially in the South-Eastern Apulia region. Specifically, the study searched for low-impact, cost-effective agricultural practices alternative to the widespread but environmentally detrimental practice of leaving the soil bare in monumental olive orchards. The practice investigated was 'grassing', i.e., soil cover with selected autochthonous plant species or commercial plant mixtures. The two alternative grassing methods were compared across 3 years under organic management. Some soil physical and chemical parameters and nearly all soil biological parameters showed differences between the two grassing types already from the first survey year. Overall, a clear positive effect of organic management was detected.

Martini et al. carried out a study on animal welfare in goats, a subject so far rather neglected by organic livestock research, at least in Italy. The study was located in Tuscany, where goat production is quite limited compared to, e.g. sheep; yet, it is important from an economic and food quality viewpoint. Three researchers developed a questionnaire including 17 indicators of goat welfare covering housing, conditions of structures and facilities, and animal health. These indicators were scored on a scale from 0 (poor) to 10 (excellent) in 21 goat farms scattered across the region, representing about $80 \%$ of the total Tuscany dairy goat farms. Of these farms, $48 \%$ were organic, $38 \%$ conventional and $14 \%$ biodynamic. Statistical differences were found among farm locations in the values of the three indicator categories. No significant differences were found in indicator values between the three management systems.

Lastly, Favilli et al. studied new organizational forms of social activities, civic engagement and networking revolving around sustainable food and foodrelated practices and their connection to human health. Based on results of the EU funded project SOLINSA, their paper analyses the transformative role of a localized food network involving different actors along the process from reorganization of a local organic food production and provision system to broader mobilization on food, health and sustainability issues. The case study analyzed is Crisoperla, an association located between Tuscany and Liguria which involves organic farmers, social farming and fishermen cooperatives, consumers' groups (solidarity-based purchase groups), other consumers' associations and technicians. The main focus of the paper is on the role of organic farming as a binder element of these networks. 
I believe that the seven papers included in this special issue witness the variety of themes covered at present by Italian organic agriculture research and their increasing attitude to tackle multidisciplinary and participatory research approaches.

I want to thank Organic Agriculture and especially its former and present editor-in-chiefs, Elizabeth Stockdale and Gerold Rahmann, for having enthusiastically supported this special issue. Many thanks to Marie Pullan, Joseph Cabusas and Jinky Amago-Devero of the Springer team for having supported me in my editorial work. Sincere thanks to the authors, the pool of Italian and international reviewers, and especially to the excellent team of five associate editors who have helped me a lot in handling the manuscripts throughout the revision process. They are the living proof of the commitment of RIRAB - which I also want to thank - to the dissemination of Italian organic research results. Their names, affiliation and tasks are listed below. I hope that the readers of Organic Agriculture would appreciate our efforts and enjoy reading this special issue.

\section{Editorial Board-Special Issue}

\section{Guest Editor}

Prof. Dr. Paolo Bàrberi, Institute of Life Sciences, Scuola Superiore Sant'Anna, Pisa (Italy), barberi@sssup.it

\section{Associate Editors}

Dr. Carla Abitabile, Consiglio per la Ricerca in Agricoltura e l'Analisi dell'Economia Agraria, Rome (Italy)

Dr. Valentina Ferrante, DIVET, Università degli Studi di Milano (Italy)

Dr. Anna La Torre, Consiglio per la Ricerca in Agricoltura e l'Analisi dell'Economia Agraria-Centro di Ricerca per la Patologia Vegetale, Rome (Italy)

Dr. Flavio Paoletti, Consiglio per la Ricerca in Agricoltura e l'Analisi dell'Economia Agraria-Centro di Ricerca per gli Alimenti e la Nutrizione, Rome (Italy)

Dr. Flavia Pizzi, CNR, Istituto di Biologia e Biotecnologia Agraria, UOS Lodi (Italy) 